\title{
STRESS, STRESSORS, AND COPING STRATEGIES BETWEEN PRE-CLINICAL AND CLINICAL MEDICAL STUDENTS AT UNIVERSITI TUNKU ABDUL RAHMAN
}

\author{
Retneswari Masilamani ${ }^{1}$, Mohammed Abdulrazzaq Jabbar ${ }^{1}$, Chang Swee Liang ${ }^{1}$, Hilary Lim Song You ${ }^{1}$, Lai \\ Jian Kai Jonathan ${ }^{1}$, Woon Pei-Suen ${ }^{1}$, Yeak Xi Yuan ${ }^{1}$ and Yong May Ling ${ }^{1}$

\begin{abstract}
${ }^{1}$ Retneswari Masilamani. Faculty of Medicine and Health Sciences. Universiti Tunku Abdul Rahman. 43000 Kajang. Malaysia. ${ }^{1}$ Mohammed Abdulrazzaq Jabbar. Faculty of Medicine and Health Sciences. Universiti Tunku Abdul Rahman. 43000 Kajang. Malaysia.

${ }^{1}$ Chang Swee Liang. Faculty of Medicine and Health Sciences. Universiti Tunku Abdul Rahman. 43000 Kajang. Malaysia. ${ }^{1}$ Hilary Lim Song You. Faculty of Medicine and Health Sciences. Universiti Tunku Abdul Rahman. 43000 Kajang. Malaysia. ${ }^{1}$ Lai Jian Kai, Jonathan. Faculty of Medicine and Health Sciences. Universiti Tunku Abdul Rahman. 43000 Kajang. Malaysia ${ }^{1}$ Woon Pei-Suen. Faculty of Medicine and Health Sciences. Universiti Tunku Abdul Rahman. 43000 Kajang. Malaysia. ${ }^{1}$ Yeak Xi Yuan. Faculty of Medicine and Health Sciences. Universiti Tunku Abdul Rahman. 43000 Kajang. Malaysia. ${ }^{1}$ Yong May Ling. Faculty of Medicine and Health Sciences. Universiti Tunku Abdul Rahman. 43000 Kajang. Malaysia.
\end{abstract}

Corresponding Author: Retneswari Masilamani

Email: retnes@gmail.com

\begin{abstract}
Stress in medical education has been inevitable among medical students. However, the prevalence of stress among preclinical and clinical medical students differed by year of study. There were several stressors reported to affect medical students. Therefore, effective coping strategies were applied to manage the stress faced by medical students. The aim of this study was to determine the prevalence of stress, stressors and coping strategies comparing pre-clinical and clinical Universiti Tunku Abdul Rahman (UTAR) medical students, and the associated stressors and stress among them. This was a cross-sectional study with a study population of 223 medical students. Universal sampling was used. A self-administered questionnaire which included socio-demographic characteristics, the General Health Questionnaire (GHQ-12), the Medical Students Stressor Questionnaire (MSSQ) and the Brief COPE Inventory were used in this study. The overall prevalence of stress among medical students was 48.15\%. Clinical students had a higher prevalence of stress (53.73\%) compared to preclinical students (39.02\%). Year 3 students had the highest prevalence of stress (64.58\%) compared to other years of study. Nearly 1 out of 2 medical students were stressed (48.15\%). Academic Related Stressor ranked the highest and Acceptance was the most practiced coping strategy. The only associated stressor with stress was Academic Related Stressor.
\end{abstract}

Keywords: stress, stressors, coping strategies, medical students, Malaysia

\section{INTRODUCTION}

Stress in medical education has been inevitable among medical students ${ }^{1}$. Boyle and Coombs reported that the main source of stress of Year 1 medical students was the fear of inability to absorb all information. A study done in India by Solanky et al. reported that the prevalence of stress encountered by medical students in India was 89.64\%; a matter of concern ${ }^{2}$. However, the level of stress perceived by medical students differed with the year of medical education. A study by Salam et al. revealed that first year medical students had a slightly higher prevalence of stress compared to third year medical students with $49.5 \%$ and $47.7 \%$ respectively ${ }^{3}$. Moreover, in a study by Fuad et al., preclinical medical students of Universiti Putra Malaysia (UPM), claimed that group activities related stressors (GARS), gender, love relationship and absence of financial support were the top risk factors of stress ${ }^{4}$. Hence, when there is stress, there should be a strategy for medical students to mitigate their stress to avert the related consequences. Effective coping strategy is paramount in overcoming the immense stress that medical students experience daily. Al-Dubai et al. reported that older medical students practiced active coping, reframing and planning more than younger medical students ${ }^{5}$. Several studies on stress among medical students have been reported in different countries and local universities ${ }^{6-11}$. However, no studies have been conducted to determine stress levels among medical students at Universiti Tunku Abdul Rahman (UTAR), Malaysia, since its inception in 2009. To address this gap, this study aimed to determine the prevalence of stress, stressors and coping strategies comparing preclinical and clinical UTAR medical students, and the associated stressors and stress among them. This study will further strengthen findings on stress among medical students, and provide recommendations on stress management strategies. 


\section{METHODS}

\section{Study design and sampling}

An analytical cross-sectional study was conducted on medical students at Universiti Tunku Abdul Rahman (UTAR), Malaysia. The study population was 223 medical students. The overall study period was 4 months; between May to September 2019. Universal sampling was used involving all 217 medical students, excluding the 6 medical students who conducted the study. Inclusion criteria were year 1 to year 5 registered UTAR medical students who volunteered to participate with written consent. The exclusion criteria were absentees on the day of data collection, those who refused to participate and the 6 medical students involved in this study.

\section{Instruments}

A self-administered questionnaire comprised of an 18 itemed socio-demographic characteristics, 12 itemed General Health Questionnaire (GHQ-12), 40 itemed Medical Students Stressor Questionnaire (MSSQ) and 28 itemed Brief COPE Inventory was used in this study.

GHQ-12 is one of the most commonly used tools to assess the stress levels among medical students ${ }^{12-14}$. The reliability coefficient of GHQ-12, in other studies, ranged from 0.78 to $0.95^{15,16}$. This questionnaire comprised of 12 manifestations of stress questions. Participants responded to each question by choosing from a Likert scale of 1 to 4 as: 'not at all', 'no more than usual', 'rather more than usual' and 'much more than usual' and the answers are scored as 0-0-1-1 based on a binary scoring method, where a score of zero to the two least symptomatic answers and a score of 1 to the two most symptomatic answers were assigned, leading to responses scored as zero or one. 'Caseness' was defined as a total questionnaire score of 4 or more ${ }^{15}$.

The MSSQ is a validated instrument developed specifically for medical students, with Cronbach's alpha values ranging from 0.64 to $0.92^{15}$. The MSSQ is a 40 itemed questionnaire used to determine the possible sources of stress based on literature, grouped into 6 main domains namely; Academic Related Stressor (ARS), Intrapersonal and Interpersonal Related Stressor (IRS), Teaching and Learning Related Stressor (TLRS), Social Related Stressor (SRS), Drive and Desire Related Stressor (DRS), and Group Activities Related Stressor (GARS). The Likert scale of the MSSQ consisted of five response choices, ranging from 0 to 4 as: 'causing no stress at all', 'causing mild stress', 'causing moderate stress', 'causing high stress' and 'causing severe stress'. The cut-off value was determined by the mean domain score where $0.00-1.00=$ mild,
$1.01-2.00=$ moderate, $2.01-3.00=$ high and 3.01 $-4.00=$ severe $^{15}$.

The most commonly used tool to identify the coping strategies of the medical students, is the Brief COPE Inventory with a Cronbach's alpha value ranging from 0.50 to $0.90^{17}$. It is an abbreviated version of the complete COPE inventory consisting of 14 scales, each scale with 2 items. The 14 scales include active coping, planning, positive reframing, acceptance, humour, religion, using emotional support, using instrumental support, selfdistraction, denial, venting, substance use, behavioural engagement and self-blame. The 4 response options were rated on a Likert scale ranging from 1-4, namely 'I haven't been doing this at all', 'I've been doing this a little bit', 'I've been doing this a medium amount', 'I've been doing this a lot', respectively ${ }^{17}$.

This study was done at the very beginning of the 2019 academic year (far from upcoming examinations), avoiding added stress and measurement bias. Each data collection session started with a short briefing on the study followed by the distribution of an information sheet. Written consent was obtained before distributing the questionnaires. It took approximately 30 minutes for the respondents to fill in the questionnaire. No identification details were collected on the questionnaire from the students to maintain confidentiality. Voluntary participation was assured with withdrawal from the study at any time allowed. Ethical clearance was obtained from UTAR Scientific and Ethical Review Committee (SERC).

\section{Statistical Analysis}

The data was analyzed using Statistical Package for Social Sciences (SPSS) version 22. Data were entered, checked for errors, explored and cleaned. Incomplete and missing data were discarded. Descriptive statistics were applied for analysis of the students' socio-demographic data and prevalence of stress, based on GHQ-12 score. Stressors using the MSSQ and coping strategies using the Brief COPE Inventory, were compared between clinical and pre-clinical medical students. A Univariable Independent Sample t-test and multivariable binary logistic regression were used to determine the associated stressors with stress among all UTAR medical students. The authors set the alpha (a) value at 0.05 with a confidence interval of $95 \%$. 


\section{RESULTS}

A response rate of $99.54 \%$ was achieved ( 216 out of 217 medical students), as one student was absent.
Table 1 shows the socio-demographic profile of the medical students comprising of $91.66 \%$ Chinese students and all were single (not shown in Table 1)

Table 1: Socio-demographic profile of medical students in UTAR $(n=216)$

\begin{tabular}{|c|c|c|}
\hline Variables & Frequency & Percentage (\%) \\
\hline \multicolumn{3}{|l|}{ Gender } \\
\hline Male & 80 & 37.04 \\
\hline Female & 136 & 62.96 \\
\hline \multicolumn{3}{|l|}{ Ethnicity } \\
\hline Chinese & 198 & 91.66 \\
\hline Indian & 16 & 7.41 \\
\hline Others & 2 & 0.93 \\
\hline \multicolumn{3}{|l|}{ Religion } \\
\hline Buddhism & 149 & 68.99 \\
\hline Christianity & 38 & 17.59 \\
\hline Hinduism & 11 & 5.09 \\
\hline Others & 18 & 8.33 \\
\hline \multicolumn{3}{|l|}{ Year of study } \\
\hline Year 1 & 44 & 20.37 \\
\hline Year 2 & 38 & 17.60 \\
\hline Year 3 & 48 & 22.22 \\
\hline Year 4 & 44 & 20.37 \\
\hline Year 5 & 42 & 19.44 \\
\hline \multicolumn{3}{|l|}{ Current posting } \\
\hline Pre-clinical & 82 & 37.96 \\
\hline Clinical & 134 & 62.04 \\
\hline \multicolumn{3}{|c|}{ Financial support for studies } \\
\hline Parents & 34 & 15.74 \\
\hline Scholarship & 2 & 0.93 \\
\hline Loan & 41 & 18.98 \\
\hline Combination & 139 & 64.35 \\
\hline \multicolumn{3}{|c|}{$\begin{array}{l}\text { Reason for choosing medical } \\
\text { education }\end{array}$} \\
\hline Own interest & 197 & 91.20 \\
\hline Family influence & 19 & 8.80 \\
\hline Age $^{*}$ & $21.63(1.97)$ & \\
\hline
\end{tabular}

The pre-clinical students consisted of Year 1 and Year 2 students, while the clinical students included Year 3, Year 4 and Year 5 students. The overall prevalence of stress in medical students was found to be $48.15 \%$ (Table 2). The highest ranked stressor was Academic Related Stressors (ARS), followed by Group Activities Related Stressors (GARS) in both pre-clinical and clinical students (Table 3 ). 
Table 2: Prevalence of stress among pre-clinical and clinical medical students (2019-2020)

\begin{tabular}{|c|c|c|}
\hline Stress & Prevalence of stress (\%) & 95\% Confidence Interval \\
\hline Overall & 48.15 & $(0.41,0.55)$ \\
\hline Pre-clinical & 39.02 & $(0.28,0.50)$ \\
\hline Clinical & 53.73 & $(0.45,0.62)$ \\
\hline \multicolumn{3}{|l|}{ Year of study } \\
\hline Year 1 & 43.18 & $(0.28,0.58)$ \\
\hline Year 2 & 34.21 & $(0.18,0.50)$ \\
\hline Year 3 & 64.58 & $(0.51,0.79)$ \\
\hline Year 4 & 54.55 & $(0.39,0.70)$ \\
\hline Year 5 & 40.48 & $(0.25,0.56)$ \\
\hline
\end{tabular}

Table 3: Stressors ranked by severity among pre-clinical and clinical medical students (2019-2020)

\begin{tabular}{|c|c|c|c|c|c|c|c|c|}
\hline \multirow[b]{2}{*}{ Variables } & \multicolumn{4}{|c|}{ Pre-clinical } & \multicolumn{4}{|c|}{ Clinical } \\
\hline & $\begin{array}{l}\text { Mean } \\
(S D)^{*}\end{array}$ & $95 \% \mathrm{Cl}^{* *}$ & Severity & Rank & $\begin{array}{l}\text { Mean } \\
(\mathrm{SD})^{*}\end{array}$ & $95 \% \mathrm{Cl}^{* *}$ & Severity & Rank \\
\hline $\begin{array}{l}\text { Academic Related } \\
\text { Stressors (ARS) }\end{array}$ & $\begin{array}{c}2.42 \\
(0.67)\end{array}$ & $\begin{array}{l}(2.27 \\
2.57)\end{array}$ & High stress & 1 & $\begin{array}{l}2.66 \\
(0.66)\end{array}$ & $\begin{array}{l}(2.55 \\
2.78)\end{array}$ & High stress & 1 \\
\hline $\begin{array}{l}\text { Intrapersonal and } \\
\text { Interpersonal } \\
\text { Related Stressors } \\
\text { (IRS) }\end{array}$ & $\begin{array}{l}1.65 \\
(0.94)\end{array}$ & $\begin{array}{l}(1.45 \\
1.86)\end{array}$ & $\begin{array}{l}\text { Moderate } \\
\text { stress }\end{array}$ & 5 & $\begin{array}{l}1.44 \\
(0.90)\end{array}$ & $\begin{array}{l}(1.28 \\
1.59)\end{array}$ & $\begin{array}{l}\text { Moderate } \\
\text { stress }\end{array}$ & 5 \\
\hline $\begin{array}{l}\text { Teaching and } \\
\text { Learning Related } \\
\text { Stressors (TLRS) }\end{array}$ & $\begin{array}{l}1.73 \\
(0.76)\end{array}$ & $\begin{array}{l}(1.57 \\
1.90)\end{array}$ & $\begin{array}{l}\text { Moderate } \\
\text { stress }\end{array}$ & 4 & $\begin{array}{c}1.64 \\
(0.82)\end{array}$ & $\begin{array}{l}(1.50 \\
1.78)\end{array}$ & $\begin{array}{l}\text { Moderate } \\
\text { stress }\end{array}$ & 3 \\
\hline $\begin{array}{l}\text { Social Related } \\
\text { Stressors (SRS) }\end{array}$ & $\begin{array}{l}1.85 \\
(0.72)\end{array}$ & $\begin{array}{l}(1.69 \\
2.00)\end{array}$ & $\begin{array}{l}\text { Moderate } \\
\text { stress }\end{array}$ & 3 & $\begin{array}{l}1.45 \\
(0.79)\end{array}$ & $\begin{array}{l}(1.32 \\
1.59)\end{array}$ & $\begin{array}{l}\text { Moderate } \\
\text { stress }\end{array}$ & 4 \\
\hline $\begin{array}{l}\text { Drive and Desire } \\
\text { Related Stressors } \\
\text { (DRS) }\end{array}$ & $\begin{array}{l}1.24 \\
(0.97)\end{array}$ & $\begin{array}{l}(1.03 \\
1.45)\end{array}$ & $\begin{array}{l}\text { Moderate } \\
\text { stress }\end{array}$ & 6 & $\begin{array}{l}0.96 \\
(0.89)\end{array}$ & $\begin{array}{l}(0.81 \\
1.11)\end{array}$ & Mild stress & 6 \\
\hline $\begin{array}{l}\text { Group Activities } \\
\text { Related Stressors } \\
\text { (GARS) }\end{array}$ & $\begin{array}{c}1.90 \\
(0.85)\end{array}$ & $\begin{array}{l}(1.71, \\
2.09)\end{array}$ & $\begin{array}{l}\text { Moderate } \\
\text { stress }\end{array}$ & 2 & $\begin{array}{l}2.20 \\
(0.92)\end{array}$ & $\begin{array}{l}(2.04 \\
2.36)\end{array}$ & High stress & 2 \\
\hline
\end{tabular}


Table 4: Rank of coping strategies practiced by pre-clinical and clinical medical students (2019-2020)

\begin{tabular}{|c|c|c|c|c|}
\hline \multirow[t]{2}{*}{ Coping Strategies } & \multicolumn{2}{|c|}{ Pre-clinical } & \multicolumn{2}{|c|}{ Clinical } \\
\hline & Mean (SD)* & Rank & Mean (SD)* & Rank \\
\hline Religion & $3.63(1.81)$ & 11 & $3.87(1.86)$ & 11 \\
\hline Active coping & $5.51(1.46)$ & 2 & $5.49(1.28)$ & 5 \\
\hline Planning & $5.46(1.34)$ & 4 & $5.51(1.54)$ & 3 \\
\hline Acceptance & $5.91(1.34)$ & 1 & $6.04(1.52)$ & 1 \\
\hline Positive reframing & $5.49(1.60)$ & 3 & $5.51(1.70)$ & 3 \\
\hline Instrumental support & $5.18(1.81)$ & 6 & $4.91(1.85)$ & 7 \\
\hline Emotional support & $4.83(1.63)$ & 7 & $4.93(1.64)$ & 6 \\
\hline Humour & $4.32(1.81)$ & 8 & 4.37 (1.97) & 9 \\
\hline Self-distraction & $5.28(1.66)$ & 5 & $5.63(1.53)$ & 2 \\
\hline Self-blame & $4.21(1.86)$ & 9 & $4.58(1.89)$ & 8 \\
\hline Venting & $4.04(1.61)$ & 10 & $4.34(1.57)$ & 10 \\
\hline $\begin{array}{l}\text { Behavioural } \\
\text { disengagement }\end{array}$ & $3.09(1.42)$ & 12 & $3.38(1.59)$ & 12 \\
\hline Denial & $2.84(1.26)$ & 13 & 3.05 (1.59) & 13 \\
\hline Substance use & $2.24(1.01)$ & 14 & $2.46(1.15)$ & 14 \\
\hline
\end{tabular}

*Mean (SD) = Mean (Standard Deviation). Minimum score was 2 and maximum score was 8. Mean score interpretations were: 2.00 = haven't been doing this at all, 2.01 to 4.00 = have been doing this a little bit, 4.01 to $6.00=$ have been doing this a medium amount, 6.01 to $8.00=$ have been doing this a lot.

Table 5: Multivariable analysis of associated stressors with stress among all medical students (2019-2020)

\begin{tabular}{lccc}
\hline \multicolumn{1}{c}{ Variables } & $\begin{array}{c}\text { Adjusted OR } \\
(\mathbf{9 5 \%} \mathrm{Cl})^{*}\end{array}$ & Wald Statistic (df)** & p-value \\
\hline Academic Related Stressors (ARS) & $\begin{array}{c}2.77 \\
(1.41,5.43)\end{array}$ & $8.75(1.00)$ & $<0.001$ \\
Intrapersonal and Interpersonal Related Stressors (IRS) & 0.99 & $0.00(1.00)$ & 0.95 \\
Teaching and Learning Related Stressors (TLRS) & $(0.66,1.47)$ & 1.40 & 0.19 \\
Social Related Stressors (SRS) & $(0.84,2.33)$ & 0.10 & 0.36 \\
Drive and Desire Related Stressors (DRS) & 0.64 & $2.73(1.00)$ & $0.85(1.00)$ \\
Group Activities Related Stressors (GARS) & $(0.38,1.09)$ & 1.20 & 0.14 \\
\hline
\end{tabular}
freedom). The model fits well. Model assumptions were met. There are no interactions and multicollinearity problems. 
At univariate levels, an Independent Sample t-test was also done to investigate the differences between the mean scores of those stressed and not stressed, and the 6 stressors. The results showed all stressors; academic related stressors (ARS) $(\mathrm{t}=$ 5.81, $\mathrm{p}$-value < 0.001), intrapersonal and interpersonal related stressors (IRS) $(\mathrm{t}=-2.43, \mathrm{p}$ value $=0.02$ ), teaching and learning related stressors (TLRS) $(t=-3.75, p$-value $<0.001)$, drive and desire related stressors (DRS) $(t=-2.16, \mathrm{p}$-value $=0.03)$, group activities related stressors (GARS) $(\mathrm{t}$ $=-5.22, \mathrm{p}$-value $<0.001$ ), had significant difference of mean scores for stress. Only the social related stressors $(S R S)(t=-2.16, p$-value $=0.06)$ showed no significant mean difference among medical students who were stressed and not stressed (Table not shown).

The multivariable binary logistic regression reported Academic Related Stressors (ARS) as the only stressor significantly associated with stress.

\section{DISCUSSION}

The prevalence of stress was $39.02 \%$ for pre-clinical students and $53.73 \%$ for clinical students in UTAR. This was different for other studies that reported pre-clinical students had higher prevalence of stress compared to the clinical students ${ }^{8,18-20}$. The higher prevalence of stress among clinical students could be explained by their learning environment in the clinical phase, where the students face patients and bedside teaching unlike the in-class teaching and learning processes in pre-clinical. Moreover, clinical students have heavier commitments and workload compared to pre-clinical students.

In UTAR, the pre-clinical and clinical students have been separated into two different settings (Preclinical at Sg. Long campus while clinical students are posted to Hospital Kuala Lumpur and Hospital Ampang). This may contribute to higher stress levels among clinical students due to them having to travel for food and to the hospital, whereas all amenities are more accessible for student at Sg. Long Campus. This was consistent with a study in Egypt $^{21}$. Year 3 medical students revealed the highest prevalence of stress $-64.58 \%$. This could be attributed to the transitional phase between preclinical and clinical. The Year 3 students are required to adapt to a new study environment and setting where one is exposed to patients for the first time, communicating with them, bed-side teaching and seeing sick and dying patients. The Year 3 students grouped into 8 or 9 students per group during their clinical posting may clarify why the Group Activities Related Stressors (GARS) were ranked second among the stressors. At UTAR, major professional examinations are held at the end of first year, third year and fifth year of the programme. Thus, added stress could be due to the major examination in third year, moreover being their first clinical examination. This was consistent with studies in Thailand, India and other Malaysian universities ${ }^{22-24}$. It was interesting to note that the prevalence of stress decreased from Year 3 to Year 5 (64.6\%, 54.5\%, 40.5\%). This could be explained by students learning to adapt and cope with stress along the way. Yusoff et al. reported in his study that the medical students may have mastered the skills required of a doctor, including communication skills and strategies to deal with patients as the years progressed ${ }^{15}$.

Among the stressors, Academic Related Stressors (ARS) and Group Activities Related Stressors (GARS) were ranked first and second respectively for both pre-clinical and clinical students. Overload of information in a short a period of time leaves minimal opportunity for students to relax and destress which may be a factor contributing towards their stress levels ${ }^{15}$. Frequent tests and examinations could lead students to become competitive and set high self-expectations for themselves to score in the exams. This finding was similar to studies conducted in Malaysia (both public and private universities), Pakistan, Netherlands, Saudi Arabia, India and Ethiopia ${ }^{13,25-31}$. Both preclinical and clinical students ranked group-related activities as second stressor - presentations and providing feedback or opinions in a group can be difficult for some students. Students overall were known to perform badly in groups as they rarely exhibited good group dynamics, as denoted in other studies in Malaysia and Netherlands ${ }^{25,26,29}$.

Socially Related Stressors (SRS) were ranked third by the pre-clinical students. This could be explained by the heavy academic workload that deprived students of enough private time for themselves, their families and friends. On the contrary, medical students in the clinical years, posted in different disciplines, meet different clinical lecturers, teachers, doctors and nurses with differing teaching styles and expectations. Thus, attempting to accommodate themselves within these varying styles, expectations and settings, may explain why the Teaching and Learning Related Stressors (TLRS) were ranked as the third stressor. The Year 3 students (being in their first year of clinical posting) exposed to bedside-teaching, the sick and deaths, together with patient contact, could explain why TLRS contributed as the third stressor; totally different from the theoretical classes in the preclinical years. Intrapersonal and Interpersonal Related Stressors (IRS) and Drive and Desire Related Stressors (DRS) were ranked fifth and last by both pre-clinical students and clinical students. This showed that medical students in UTAR rarely faced conflict with other students, lecturers, doctors, 
nurses and hospital staff. The DRS being scored last could be explained by UTAR medical students being genuinely interested in studying medicine. This was consistent with the findings under sociodemography (Table 1), which revealed that $91.20 \%$ of the medical students in UTAR chose to study medicine due to their own interests. A study from Pakistan revealed similar findings ${ }^{28}$.

In this study, only Academic Related Stressors (ARS) was significantly associated with stress among medical students out of all six stressor domains. This emphasizes the need to review the current curriculum and address the specific academic stressors causing stress. The most practiced coping strategy among pre-clinical and clinical medical students was acceptance, unlike in Nepal where positive reframing was ranked first ${ }^{20}$. Generally, medical students in UTAR used more positive coping strategies such as acceptance, positive reframing and active coping than negative coping strategies, namely; behaviour disengagement, denial and substance use. An encouraging point to note is that these negative coping strategies were ranked very low, which otherwise could result in chronic stress and anxiety. Other studies have also consistently reported similar results ${ }^{29,32-33}$.

This was a promising finding in contrast to studies in the United Kingdom and Ethiopia where alcohol abuse, drug use, khat chewing and cigarette smoking were commonly practised by medical students ${ }^{31,34}$. This study also found religious coping had a relatively lower ranking (eleventh place) in comparison to other Malaysian studies which ranked religion as the top most coping strategy ${ }^{5,13}$. This relates to the fact that Malaysian public universities have a majority of Muslim students meanwhile UTAR medical students are predominantly Chinese. This finding was in line with a study in another university in Malaysia and the United Arab Emirates ${ }^{5,35}$. The World Health Organisation/European Haematology Association (WHO/EHA) guidelines state that there are no standard guidelines for coping strategies but rather depend on cultural and socio-economic factors ${ }^{36}$. This goes to support the findings that coping strategies revealed by medical students could be based on one's socio-economic status and culture.

This study has several limitations, namely; the study design did not allow a cause-effect relationship to be studied. Participants underscoring or providing socially desirable answers may have led to response bias. Since this study was only conducted in a single university, the findings are not generalizable to other state universities or to all medical students in Malaysia. The small sample size (though universal sample) may have contributed to less positive findings. All the above limitations call for caution in interpreting the findings.

\section{CONCLUSION}

The prevalence of stress among clinical medical students was greater than pre-clinical medical students. Academic Related Stressors (ARS) topped the list of six stressor domains. This study showed that only ARS was significantly associated with stress among medical students. Thus, reviewing the current medical curriculum and organizing mindfulness workshop are recommended to help medical students cope with stress. Establishing direct channels for acquiring appointments (preventing the associated stigma) while seeking counselling services, will go a long way in addressing stress in medical education.

\section{ACKNOWLEDGEMENT}

The authors would like to specially thank Universiti Tunku Abdul Rahman (UTAR) for funding this research project and the Dean of the Faculty of Medicine and Health Sciences for his continuous support in this endeavour. The authors would also like to express their deepest appreciation to their supervisor, for her dedication, unceasing guidance and assistance throughout the whole study. Last but not least, the authors would like to say 'a big thank you' to the participants; all medical students in UTAR for participating in this study.

\section{Conflicts of interest}

The authors declare no conflicts of interest

\section{REFERENCES}

1. Boyle BP and Coombs RH. Personality Profiles related to Emotional Stress. 1971.

2. Solanky P, Desai B, Kavishwar A, et al. Study of psychological stress among undergraduate medical students of government medical college, Surat. Int $J$ Med Sci Public Health. 2012; 1 (2): 38.

3. Salam A, Mahadevan R, Rahman AA, et al. Stress among First and Third Year Medical Students at University Kebangsaan Malaysia. Pak J Med Sci. 2015; 31(1): 169173. DOI: 10.12669/pjms.311.6473.

4. Fuad MD, Al-Zurfi BM, AbdulQader MA, et al. Prevalence and risk factors of stress, anxiety and depression among medical students of a private medical University in Malaysia in 2015. Educ Med J. 2015; 7. 
5. Al-Dubai SAR., Al-Naggar RA, Alshagga MA et al. Stress and Coping Strategies of Students in a Medical Faculty in Malaysia. Malays J Med Sci. 2011; 18(3): 57-64.

6. Abdulghani HM, AlKanhal AA, Mahmoud ES, et al. Stress and its effects on medical students: a cross-sectional study at a college of medicine in Saudi Arabia. J Health Popul Nutr. 2011; 29(5):516.

7. Mane Abhay B, Krishnakumar MK, Niranjan Paul $C$ et al. Differences in perceived stress and its correlates among students in professional courses. J Clin Diagn Res. 2012; 5(6): 1228-1233.

8. Koochaki GM, Charkazi A, Hasanzadeh A, et al. Prevalence of stress among Iranian medical students: a questionnaire survey. East Mediterr Health J. 2011; 17(7):593-8.

9. Firth J. Levels and sources of stress in medical students. Br Med J (Clin Res Ed). 1986; 292(6529):1177-80.

10. Johari $A B$, Hassim IN. Stress and coping strategies among medical students in national university of Malaysia, Malaysia University of Sabah and University Kuala Lumpur Royal College of Medicine Perak. Journal of Community Health. 2009; 15(2):106-15.

11. Salam A, Yousuf R, Bakar SM,et al. Stress among medical students in Malaysia: A systematic review of literatures. Int Med J. 201; 20(6):649-55.

12. McDowell I. Measuring health: a guide to rating scales and questionnaires, 3rd Ed. New York; Oxford University Press. 2006.

13. Yusoff MS, Yee LY, Wei LH, Siong TC, et al. A study on stress, stressors and coping strategies among Malaysian medical students. International Journal of Students' Research. 2011; 1(2): 45-50.

14. Yusoff MSB, Abdul Rahim AF and Yaacob MJ. The Prevalence of Final Year Medical Students with Depressive Symptoms and Its Contributing Factors. Int Med J. 2011; 18 (4): 305-309.

15. Yusoff MS, Rahim AF, editors. The medical student stressor questionnaire (MSSQ) Manual. Universiti Sains Malaysia; 2010.
16. Eva EO, Islam MZ, Mosaddek AS,et al. Prevalence of stress among medical students: a comparative study between public and private medical schools in Bangladesh. BMC research notes. 2015; 8(1):327.

17. Carver CS. You want to measure coping but your protocol'too long: Consider the brief cope. Int J Behav Med. 1997; 4(1):92.

18. Yusoff MS. Associations of pass-fail outcomes with psychological health of first-year medical students in a Malaysian medical school. Sultan Qaboos Univ Med J. 2013; 13(1):107.

19. Yusoff MS, Rahim AF, Baba AA, Ismail SB, $\mathrm{Pa} M \mathrm{MN}$. Prevalence and associated factors of stress, anxiety and depression among prospective medical students. Asian J Psychiatr. 201; 6(2):128-33.

20. Sreeramareddy CT, Shankar PR, Binu VS, et al. Psychological morbidity, sources of stress and coping strategies among undergraduate medical students of Nepal. BMC Med Educ. 2007; 7(1):26.

21. El-Masry R, Ghreiz SM, Helal RM, et al. Perceived stress and burnout among medical students during the clinical period of their education.. Ibnosina J Med Biomed Sci. 2013; 5 (4):179-87.

22. Saipanish R. Stress among medical students in a Thai medical school. Medical teacher. 2003; 25 (5):502-6.

23. Supe AN. A study of stress in medical students at Seth GS Medical College. Journal of postgraduate medicine. 1998; $44(1): 1$.

24. Abdulghani HM, AlKanhal AA, Mahmoud ES, et al. Stress and its effects on medical students: a cross-sectional study at a college of medicine in Saudi Arabia. J Health Popul Nutr. 2011; 29(5):516.

25. Siraj HH, Salam A, Roslan R,et al. Stress and its association with the academic performance of undergraduate fourth year medical students at Universiti Kebangsaan Malaysia. The International Medical Journal Malaysia. 2014; 13 (1):19-24.

26. Masilamani R, Aung $M M$, Bhagat $V$, et al. Prevalence of Stress and Associated Stressors among Medical Students: A 
Comparative Study between a Private and Public Medical School in Malaysia. Res $J$ Pharm Technol. 2018; 11 (6):2531-7.

27. Elias H, Ping WS, Abdullah MC. Stress and academic achievement among undergraduate students in Universiti Putra Malaysia. Procedia Soc Behav Sci. 2011 Jan 1; 29: 646-55.

28. Gazder DP, Ahmad F, Danish SH. Stressors, Coursework Stress and Coping Strategies among medical students in a private medical school of Karachi, Pakistan. Education in Medicine Journal. 2014; 6(3).

29. Shankar PR, Balasubramanium R, Ramireddy R, et al. Stress and Coping Strategies among Premedical and Undergraduate Basic Science Medical Students in a Caribbean Medical School. Education in Medicine Journal. 2014; 6 (4).

30. Krishnappa K, Singh NP, Jain PK,et al. Medical School and Stress: A Crosssectional Study of Stress among Medical Students in Uttar Pradesh University of Medical Sciences in district Etawah. Indian J Community Health. 2018; 30 (3).

31. Melaku L, Mossie A, Negash A. Stress among medical students and its association with substance use and academic performance. J Biomed Educ. 2015.

32. Wu L, Farquhar J, Ma J, et al. Understanding Singaporean medical students' stress and coping. Singapore Med J. 2018; 59 (4):172.

33. Goyal P, Upadhyah AA, Pandit DP, et al. A study of stress, stressors, and coping strategies among students of a newly established medical college in South Gujarat. Natl J Physiol Pharm Pharmacol. 2016; 6 (6):604-11.

34. Pickard $M$, Bates $L$, Dorian $M$, et al. Alcohol and drug use in second-year medical students at the University of Leeds. Medical education. 2000:34 (2):148-50.

35. Gomathi KG, Ahmed S, Sreedharan J. Causes of stress and coping strategies adopted by undergraduate health professions students in a university in the United Arab Emirates. Sultan Qaboos Univ Med J. 2013; 13 (3):437.

36. WHO/EHA. Overview Coping Mechanisms. Emergency health training programme for Africa. Panafrican Emergency Training Centre, Addis Ababa. 1999: 3-13. 